\title{
AVALIAÇÃO DA RESISTÊNCIA DO SOLO À PENETRAÇÃO EM DIFERENTES SOLOS COM A VARIAÇÃO DO TEOR DE ÁGUA
}

\author{
RENATO L. DE ASSIS ${ }^{1}$, GILMAR D. LAZARINI², KLÉBER P. LANÇAS ${ }^{3}$, \\ ALBERTO CARGNELUTTI FILHO ${ }^{4}$
}

\begin{abstract}
RESUMO: Com os crescimentos da população e da demanda por alimentos, novas tecnologias têm surgido visando ao aumento da produtividade e à redução nos custos de produção. Se por um lado essas tecnologias elevam a produção e reduzem os custos, por outro o tráfego intenso de máquinas e tratores alteram a estrutura do solo, tornando-o compactado, comprometendo, assim, a produtividade agrícola. Neste trabalho, relacionou-se o teor de água do solo com a sua resistência à penetração, para quatro tipos de solo e quatro condições de umidade, utilizando penetrômetro hidráulico-eletrônico com sistema de navegação DGPS. Os resultados mostraram que ocorreram modificações nas condições de atrito entre o cone e o solo com o aumento do teor de água, facilitando a penetração da haste, tornando o solo mais plástico devido à ação lubrificante entre as suas partículas. Os maiores valores de resistência do solo à penetração foram detectados mais próximos do limite de contração do solo. Houve correlação negativa entre o índice de cone e o teor de água, sendo a função de melhor ajuste a linear decrescente para todos os solos, com altos coeficientes de determinação. Nas condições de solo mais úmido, os valores de resistência do solo à penetração podem ser considerados não impeditivos para o crescimento de raízes. O tipo de solo também se mostrou significativamente influente nos resultados de índice de cone.
\end{abstract}

PALAVRAS-CHAVE: densidade do solo, índice de cone, limites de consistência.

\section{EVALUATION OF SOIL RESISTANCE TO PENETRATION IN DIFFERENT SOILS WITH VARYING MOISTURE CONTENTS}

\begin{abstract}
As human population and demand for food grow, new technologies have emerged to increase productivity and reduce production costs. If these technologies on the one hand have increased production and reduced costs, on the other hand the intense traffic of machinery and tractors have modified the soil structure, causing compaction and compromising agricultural productivity. In this study we relate soil moisture to soil resistance to penetration in four soil types under four moisture conditions, using a hydraulic-electronic penetrometer containing a DGPS navigation system. The results showed there were changes in the friction conditions between the cone and the soil as moisture increased, facilitating rod penetration and making the soil more plastic due to the lubricating action among its particles. The highest values of soil resistance to penetration were detected around the soil shrinkage limit. There was a negative correlation between cone index and moisture. The best fit for all soils was provided by a decreasing linear function, with high coefficients of determination. Under higher soil moisture conditions, soil resistance to penetration values can be considered not to prevent root growth. Soil type also had a significant impact on cone index results.
\end{abstract}

KEYWORDS: soil density, cone index, consistency limits.

\footnotetext{
${ }^{1}$ Eng ${ }^{\circ}$ Agrícola, Professor da Faculdade de Agronomia da FESURV, Universidade de Rio Verde, Rio Verde - GO, Fone: (0XX64) 3620.2213, assis@fesurv.br

${ }^{2}$ Eng $^{\circ}$ Agrônomo, FCA/UNESP-Botucatu - SP.

${ }^{3}$ Eng ${ }^{\circ}$ Mecânico, FCA/UNESP-Botucatu, NEMPA - Núcleo de Ensaio de Máquinas e Pneus Agroflorestais, kplancas@fca.unesp.br

${ }^{4}$ Eng ${ }^{\mathrm{O}}$ Agrônomo, Universidade Federal de Santa Maria, Departamento de Fitotecnia, Santa Maria - RS, cargnelutti@ pq.cnpq.br

Recebido pelo Conselho Editorial em: 14-4-2008

Aprovado pelo Conselho Editorial em: 18-9-2009
}

Eng. Agríc., Jaboticabal, v.29, n.4, p.558-568, out./dez. 2009 


\section{INTRODUÇÃO}

A compactação pode ser definida como sendo a alteração na estrutura física do solo de modo a reduzir os espaços internos que normalmente são ocupados por água e ar. Em decorrência disso, a disponibilidade desses elementos no solo torna-se reduzida, dificultando, assim, o bom desenvolvimento das culturas. A compactação, além de proporcionar restrição ao crescimento radicular, afeta a infiltração e a condutividade hidráulica, além de promover alterações nos processos químicos e biológicos no solo (CAMARGO \& ALLEONI, 1997).

De acordo com CHANCELLOR (1977), o volume total de um solo é formado pelo volume de partículas minerais e por poros entre as partículas. Esse solo é considerado compactado quando a proporção de macroporos em relação à porosidade total é inadequada para o eficiente desenvolvimento da planta. Segundo alguns autores, o solo ideal é aquele que tem a porosidade total de $50 \%$, sendo um terço, cerca de $17 \%$, de macroporos ocupados pelo ar do solo, e dois terços, cerca de 33\%, de microporos responsáveis pela retenção de água (KIEHL, 1979).

A consistência do solo, dentre as propriedades físico-hídrico-mecânicas do solo que descreve a resposta do solo à ação das forças externas que tendem a deformá-lo e podem ocasionar fluxo, fratura ou compressão do solo (FORSYTHE, 1975), varia conforme o teor de água do solo. Um solo pode apresentar vários estados de consistência, conforme o conteúdo de água, e é na condição de solo friável (abaixo do limite plástico) que se recomenda a realização das operações motomecanizadas, em função da mínima coesão entre as partículas do solo e da menor adesão do solo às ferramentas de preparo e de semeadura (ASHBURNER \& SIMS, 1984).

A resistência do solo à penetração (RP) tem sido utilizada, ao longo de muitos anos, com inúmeras aplicações em diversas áreas da pesquisa agronômica, sendo várias já consolidadas, tais como: detecção de camadas compactadas, em estudo da ação de ferramentas de máquinas no solo, prevenção de impedimento mecânico ao desenvolvimento do sistema radicular das plantas, predição da força de tração necessária para execução de trabalhos e para conhecimento de processos de umedecimento e de ressecamento (CUNHA et al., 2002).

A RP, além da dependência de fatores intrínsecos do solo (textura, estrutura, mineralogia), é altamente dependente da umidade do solo (GOMES \& PEÑA, 1996). Em condição de baixa umidade, a água encontra-se num maior estado de tensão nos poros do solo. Além dessa tensão, somam-se as forças de coesão e de adesão já existentes entre os sólidos do solo, resultando em maior resistência à deformação ou à penetração de raízes numa condição de baixa umidade (CUNHA et al., 2002). Com o aumento do teor de água, decresce a atuação das forças de coesão entre as partículas do solo e o atrito interno, provocando, então, a diminuição da RP (CUNHA et al., 2002).

Vários autores recomendam que a RP seja medida com o teor de água próximo à capacidade de campo (HENDERSON, 1989), situação em que se consegue boa correlação entre a densidade do solo, a resistência à penetração e o crescimento radicular. No entanto, o período em que o solo permanece na capacidade de campo é pequeno, de modo que a resistência do solo pode rapidamente variar de níveis não impeditivos para impeditivos com a secagem do mesmo.

Contrariando a recomendação de trabalhos mais antigos (HENDERSON, 1989; ARSHAD et al., 1996), não é recomendável a determinação da RP quando o solo se encontra na capacidade de campo ou próximo dela, pois a água diminui a capacidade de detecção das diferenças existentes nos resultados obtidos. A razão é que os equipamentos utilizados anteriormente eram, na grande maioria, manuais e dependiam da força do operador, não possibilitando, dessa forma, a obtenção de dados em solos com baixo teor de água. Para comprovar essa recomendação, GUERRA et al. (2000), em estudo com penetrômetro hidráulico-eletrônico, constataram a influência do teor de água na determinação do índice de cone, ou seja, a RP numa determinada profundidade, em que a presença da água inibiu a diferenciação da compactação pelo efeito lubrificante que provoca no solo, deixando-o muito plástico e facilitando a penetração da haste, indicando que, para melhor 
sensibilidade dos efeitos da carga, devem-se tomar os dados de RP com o solo com baixo teor de água.

As diferenças entre os penetrômetros e o sistema radicular dificultam o estabelecimento de boa correlação entre a pressão exercida pelas raízes e a RP medida no mesmo local com o penetrômetro. Segundo BENGOUGH \& MULLINS (1990), numa mesma condição de solo, a RP avaliada pelo penetrômetro pode resultar em valores de 2 a até 8 vezes mais elevados que as pressões exercidas pelas raízes.

A resistência do solo à inserção de uma ponta cônica com ângulo sólido de 30 (ASAE, 1999) é a maneira rápida e fácil de medir a RP a várias profundidades, sendo muito útil para relacionar fatores de resistência do solo à elongação radicular, avaliação da compactação em diferentes sistemas de preparo, predição de tração, resistência ao rolamento e outros (SANTOS \& LANÇAS, 1999).

SANTOS \& LANÇAS (1999) utilizaram um penetrômetro hidráulico-eletrônico e verificaram que a grande vantagem desse equipamento em relação aos manuais é que o primeiro opera com velocidade de penetração constante (ASAE, 1999), independentemente da resistência oferecida pelo solo, rapidez na determinação (entre 18 e 20 segundos por determinação), o que é difícil de se obter com os de acionamento manual em condições de baixo teor de água.

Apesar de a RP ser afetada pela textura, pela densidade do solo e pelo teor de água, CANARACHE (1990) sugere que valores acima de 2,5 MPa começam a restringir o pleno crescimento das raízes da maioria das plantas. Segundo BEUTLER et al. (2006), valores de 2,0 a 3,0 MPa são limitantes à produtividade de soja, enquanto MEROTTO \& MUNDSTOCK (1999) indicam que RP maior que 3,5 MPa causa severa limitação ao crescimento de plantas de trigo. Segundo ROSOLEM et al. (1999), a RP da ordem de 1,3 MPa reduz à metade o crescimento das raízes seminais adventícias do milho. TORRES \& SARAIVA (1999), em experimentos com soja em Latossolo Roxo, observaram valores de resistência em torno de 3,5 a 6,5 MPa (solo na consistência friável) como causadores de possíveis problemas de impedimento mecânico.

O penetrômetro é um instrumento importante na avaliação da compactação do solo, porém os resultados obtidos por meio dele devem ser inseridos em um contexto maior de avaliação da compactação, contemplando, além do uso correto do equipamento (numa mesma condição de umidade, dentro da consistência friável, mas próximo do limite de contração), o histórico de produtividade da propriedade em diferentes glebas e abertura de trincheiras para a verificação do sistema radicular (TORRES \& SARAIVA, 1999).

Este trabalho teve o objetivo de avaliar a interação entre a resistência do solo à penetração, umidade do solo e tipo de solo.

\section{MATERIAL E MÉTODOS}

A presente pesquisa foi realizada na Faculdade de Ciências Agronômicas - UNESP, Câmpus de Botucatu - SP, localizada geograficamente em $22^{\circ} 51^{\prime}$ ' de latitude sul e $48^{\circ} 26^{\prime}$ de longitude oeste, e altitude média de $840 \mathrm{~m}$, sendo o clima classificado como temperado quente (mesotérmico), com chuvas no verão e seca no inverno (Cwa - Köeppen), e a temperatura média do mês mais quente superior a $22{ }^{\circ} \mathrm{C}$ (CUNHA et al., 1999).

Utilizaram-se quatro diferentes tipos de solos localizados dentro da Fazenda Lajeado para a avaliação da RP, com cobertura vegetal caracterizada por gramíneas e vegetação natural, sem cultivo, sem mobilização ou alteração das suas propriedades físicas, localizados em áreas planas, com declividade inferior a $1 \mathrm{~cm} \mathrm{~m}^{-1}$. A escolha dos solos com diferentes texturas visou a avaliar $\mathrm{o}$ efeito das diferentes distribuições granulométricas na RP. Os solos avaliados foram classificados segundo EMBRAPA (1999): Latossolo Vermelho distrófico (LVd), Nitossolo Vermelho distroférrico (NVdf), Latossolo Vermelho distroférrico (LVdf) e Nitossolo Vermelho distrófico $(\mathrm{NVd})$. 
Para a determinação da RP, utilizou-se de penetrômetro hidráulico-eletrônico, construído por SANTOS \& LANÇAS (1999), com sistema de navegação DGPS (Diferential Global Positioning System) que permite o retorno ao local estabelecido nas diversas fases do experimento, além do tempo entre 18 e 20 segundos por determinação.

O sistema, composto por um pistão hidráulico, uma célula de carga, uma haste de aço contendo uma ponteira cônica de ângulo sólido de $30^{\circ}$, foi acionado pelo sistema hidráulico do trator ("controle remoto") para a obtenção da pressão necessária para cravar o cone na direção normal (perpendicular) ao solo. A velocidade constante de $1.820 \mathrm{~mm} \mathrm{~min}^{-1}$, independentemente da resistência do solo (ASAE, 1999), foi obtida por meio da instalação de válvula de controle de vazão no circuito hidráulico.

A obtenção, o registro e o armazenamento dos dados de RP foram realizados por um sistema eletrônico, formado pelos seguintes componentes: célula de carga, potenciômetro utilizado como sensor de profundidade, sistema de aquisição de dados ("microlloger"), sistema de armazenamento de dados, microcomputador e programa para análise dos dados ou planilha eletrônica. Foi utilizado para o processamento eletrônico dos dados, o programa desenvolvido por CASTRO NETO et al. (1999).

Para a determinação da densidade do solo, foi utilizado o método do torrão impermeabilizado com parafina, EMBRAPA (1997). O teor de água do solo no momento da determinação da RP foi determinada nas faixas de $0-20$ e $20-40 \mathrm{~cm}$ de profundidade, em amostras retiradas com trado holandês, que foram secas em estufa a $105{ }^{\circ} \mathrm{C}$ durante $24 \mathrm{~h}$, segundo método da EMBRAPA (1997). Em cada solo, foram selecionadas três áreas de $10 \times 5 \mathrm{~m}\left(50 \mathrm{~m}^{2}\right)$, nos quais se avaliou a RP em quatro condições com diferentes umidades, e para cada umidade foram realizadas oito determinações de RP por área, com distância de aproximadamente $30 \mathrm{~cm}$ entre cada determinação. Procurou-se representar diferentes faixas de umidade para cada solo. Em razão da pequena variação do teor de água para cada faixa e em cada profundidade no momento da determinação da RP, considerou-se um valor médio entre as profundidades.

Amostras deformadas coletadas nos diferentes solos, nas profundidades de 0-20 e 20-40 cm, foram utilizadas para a determinação dos limites de liquidez (LL), do limite de plasticidade (LP) e do limite de contração (LC) e da textura do solo, segundo metodologias da EMBRAPA (1997).

Posteriormente, foram avaliados os testes das hipóteses entre os solos e os teores de água, e a análise fatorial dessas variáveis. Os dados foram ajustados por meio de regressão a fim de buscar um modelo de equação que melhor representasse a RP em função do teor de água. A análise estatística foi realizada por meio do SAS (1995).

\section{RESULTADOS E DISCUSSÃO}

Os solos estudados apresentaram grande variação nos percentuais de areia, argila e silte (Tabela 1), objetivo proposto para o estudo. Não ocorreram grandes variações nos valores de densidade nos solos estudados em razão de não serem cultivados. A densidade do solo entre as duas profundidades em cada solo apresentou pequenas variações, fato importante na avaliação da resistência do solo à penetração (Tabela 1).

Analisando a Tabela 2, observa-se que o solo LVd apresentou faixa de friabilidade estreita, em razão do seu elevado percentual de areia, enquanto o $\mathrm{NVd}$ apresentou faixa de friabilidade mais ampla, em decorrência do maior percentual de argila. A textura afeta a retenção de água, pois, diretamente, determina a área de contato entre as partículas sólidas e a água, e determina as proporções de poros de diferentes tamanhos (REICHARDT, 1990). 
TABELA 1. Caracterização da textura (areia, argila e silte), classificação textural e densidade do solo nas profundidades de 0-20 e 20-40 cm nos solos estudados. Texture characterization (sand, clay, and silt), texture classification, and bulk density at depths from 0-20 and from $20-40 \mathrm{~cm}$ in soils studied.

\begin{tabular}{ccccccc}
\hline $\begin{array}{c}\text { Tipo de } \\
\text { Solo }\end{array}$ & Prof. & Areia* & $\begin{array}{c}\text { Argila } \\
\text {-- cm --- }\end{array}$ & Silte & Classificação Textural & $\begin{array}{c}\text { Densidade do Solo } \\
\text {-------- } \mathrm{g} \mathrm{kg} \mathrm{m}^{-3} \text {--- }\end{array}$ \\
\hline \multirow{2}{*}{ LVd } & $0-20$ & 750 & 205 & 45 & Franco-Argilo-Arenosa & 1,51 \\
& $20-40$ & 740 & 200 & 60 & Franco-Argilo-Arenosa & 1,56 \\
\hline \multirow{2}{*}{ NVdf } & $0-20$ & 503 & 440 & 57 & Argilo-arenosa & 1,50 \\
& $20-40$ & 450 & 460 & 90 & Argilo-arenosa & 1,47 \\
\hline \multirow{2}{*}{ LVdf } & $0-20$ & 410 & 488 & 102 & Argila & 1,57 \\
& $20-40$ & 415 & 450 & 135 & Argila & 1,54 \\
\hline \multirow{2}{*}{ NVd } & $0-20$ & 280 & 658 & 62 & Muito argilosa & 1,43 \\
& $20-40$ & 290 & 630 & 80 & Muito argilosa & 1,47 \\
\hline
\end{tabular}

*Médias de quatro repetições.

TABELA 2. Valores do limite de liquidez (LL), limite de plasticidade (LP) e limite de contração (LC) para as áreas em estudo; médias de três repetições. Liquid limit (LL), plastic limit (PL), and shrinkage limit (SL) values for the areas under study. Means of three replicates.

\begin{tabular}{|c|c|c|c|c|c|}
\hline \multirow{2}{*}{ Tratamento } & Profundidade & LL & LP & $\mathrm{LC}$ & $\mathrm{FF}^{(1)}$ \\
\hline & ------cm------ & ----------- & $-\cdots--\cdot$ & $s^{-1}-\cdots$ & -------------- \\
\hline \multirow{2}{*}{ LVd } & $0-20$ & 0,18 & 0,17 & 0,16 & 0,01 \\
\hline & $20-40$ & 0,18 & 0,16 & 0,15 & 0,01 \\
\hline \multirow{2}{*}{ NVdf } & $0-20$ & 0,28 & 0,25 & 0,14 & 0,11 \\
\hline & $20-40$ & 0,33 & 0,22 & 0,18 & 0,04 \\
\hline \multirow{2}{*}{ LVdf } & $0-20$ & 0,36 & 0,24 & 0,16 & 0,08 \\
\hline & $20-40$ & 0,31 & 0,22 & 0,15 & 0,07 \\
\hline \multirow{2}{*}{$\mathrm{NVd}$} & $0-20$ & 0,39 & 0,27 & 0,17 & 0,10 \\
\hline & $20-40$ & 0,35 & 0,29 & 0,16 & 0,13 \\
\hline
\end{tabular}

A pequena variação da umidade para cada faixa e em cada profundidade, no momento da determinação da RP e da densidade do solo (Tabela 1), explica os valores de RP constantes até $40 \mathrm{~cm}$ com elevada umidade do solo (Figura 1). Em solos cujas propriedades mecânicas dependem essencialmente das forças de coesão, a RP permanece praticamente constante ao longo da profundidade. Com o aumento do teor de água, decresce a atuação das forças de coesão entre as partículas do solo e o atrito interno, promovendo a diminuição da RP (CUNHA et al., 2002).

A RP apresentou grande variação dentro de cada solo, em função da variação do teor de água (Figuras 1 e 2). As maiores diferenças de RP são observadas para os menores teores de água. Observa-se em todos os solos a dependência da RP com o teor de água do solo, ou seja, à medida que se aumenta o teor de água, diminui-se a RP, e vice-versa. Resultados semelhantes foram observados por CUNHA et al. (2002) e SANTOS \& LANÇAS (1999). Segundo KLEIN et al. (1998), TORRES \& SARAIVA (1999) e PEREIRA et al. (2002), em condições de solo muito úmido, regiões compactadas não são detectadas. Em condições de campo, a condição de teor de água dentro do intervalo plástico é mantida apenas por um curto período de tempo, de modo que a resistência aumenta com a secagem do solo, e em períodos de déficit hídrico poderão ocorrer impedimentos à penetração de raízes. 

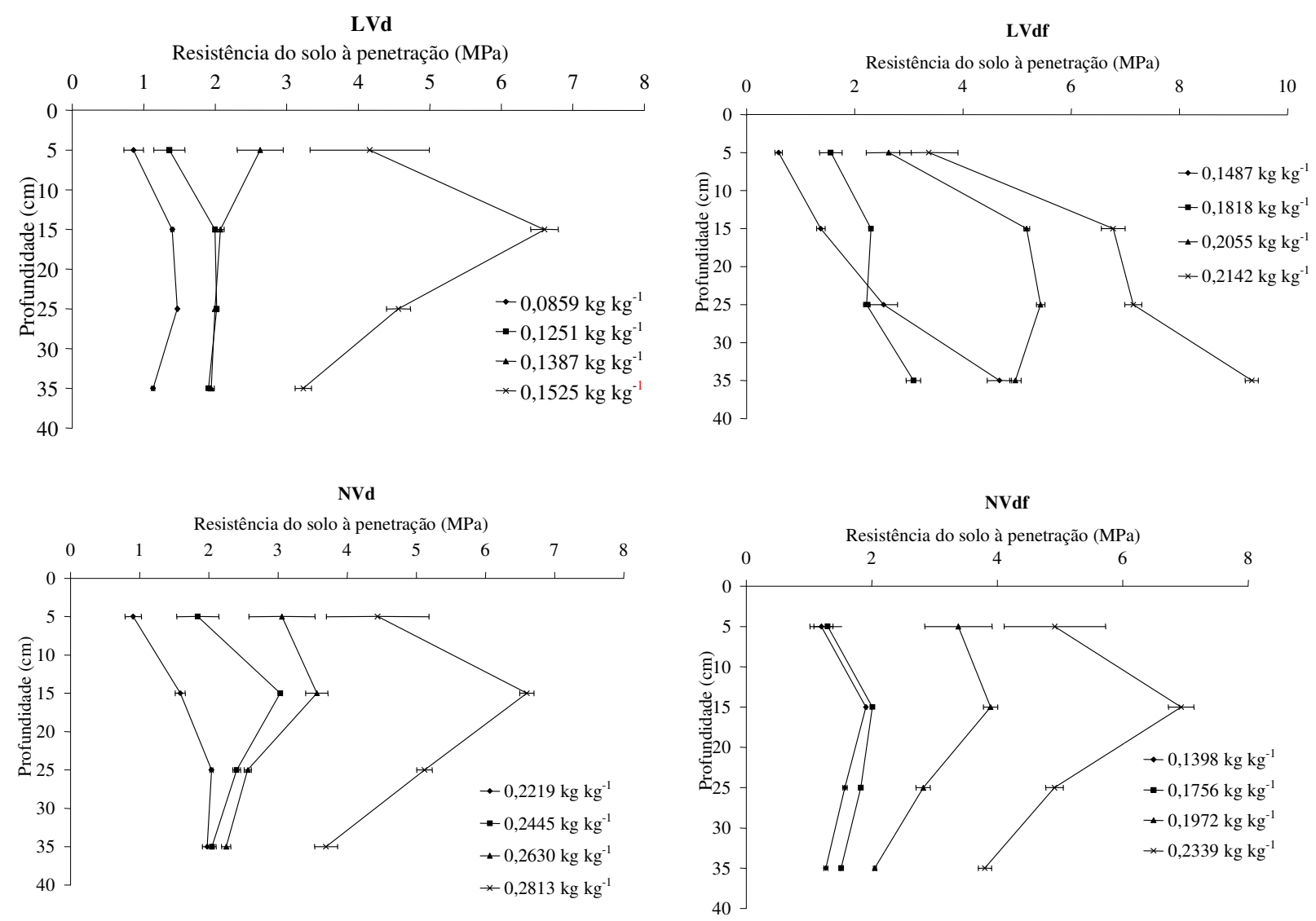

FIGURA 1. Resistência do solo à penetração nas diferentes umidades e profundidades e para os diferentes tipos de solos. As barras indicam os valores do erro-padrão da média e a sobreposição destas denota a ausência de diferenças entre as médias da RP entre as diferentes umidades para cada tipo de solo. Soil resistance to penetration at different soil moisture and depth values for different soil types. The bars indicate standard error of the mean values, while bar overlapping denotes a lack of difference between RP means for the various moisture values in each soil type.

Quando se compara a RP em diferentes sistemas de manejo, a presença ou ausência de diferenças entre os sistemas podem ser confundidas com as influências desses sobre o teor de água do solo (CHANCELLOR, 1977). Dessa forma, é importante o controle do teor de água na determinação da RP, permitindo, assim, evidenciar os efeitos dos sistemas de manejo sobre a estrutura do solo.

Na Figura 2, é apresentado o índice de cone em função do teor de água para os diferentes solos estudados, apresentando também as faixas dos erros que representam as médias dos desvios-padrão dos pontos amostrais, para o índice de significância de 5\%.

Para a RP, nos diferentes solos, observou-se variação linear decrescente significativa com a variação no teor de água do solo (Figuras 2 e 3). Resultados semelhantes foram observados por CUNHA et al. (2002); entretanto, segundo CAMPBELL \& O'SULLIVAN (1991), é recomendável relacionar informações complementares relacionadas ao tipo de solo e à densidade do solo para se ter maior confiabilidade nos resultados. 
LVd
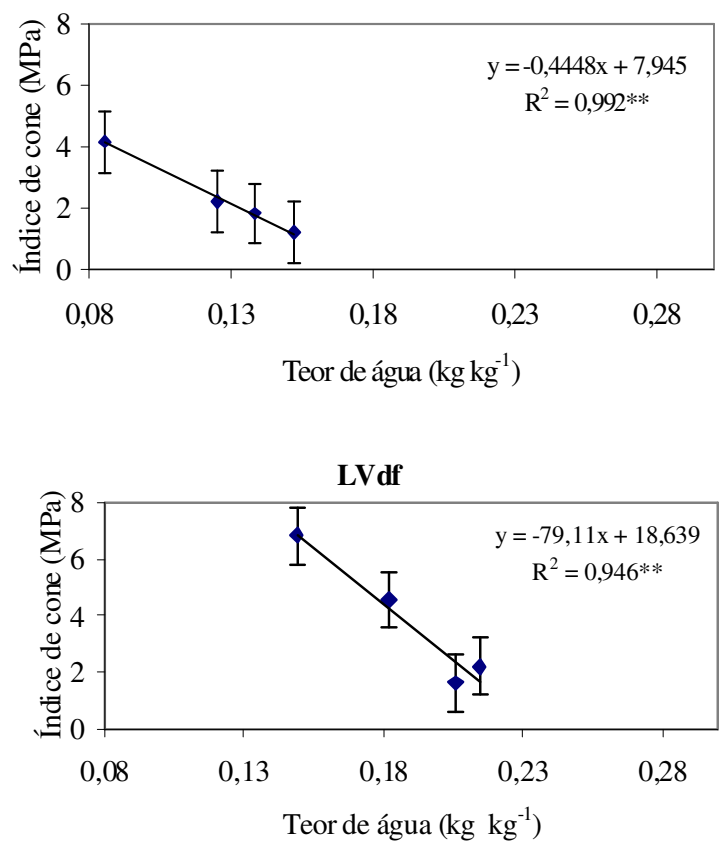

NVdf
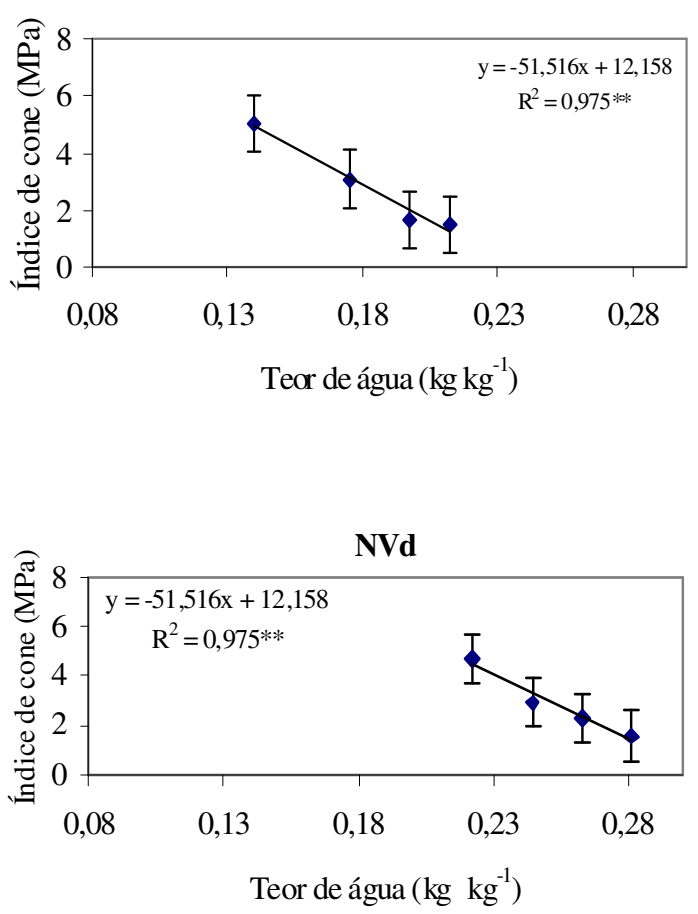

FIGURA 2. Equações entre índice de cone e teor de água para os diferentes solos estudados. **Significativo a $1 \%$. Equations between cone index and moisture for the various soils studied. ** Significant at $1 \%$.

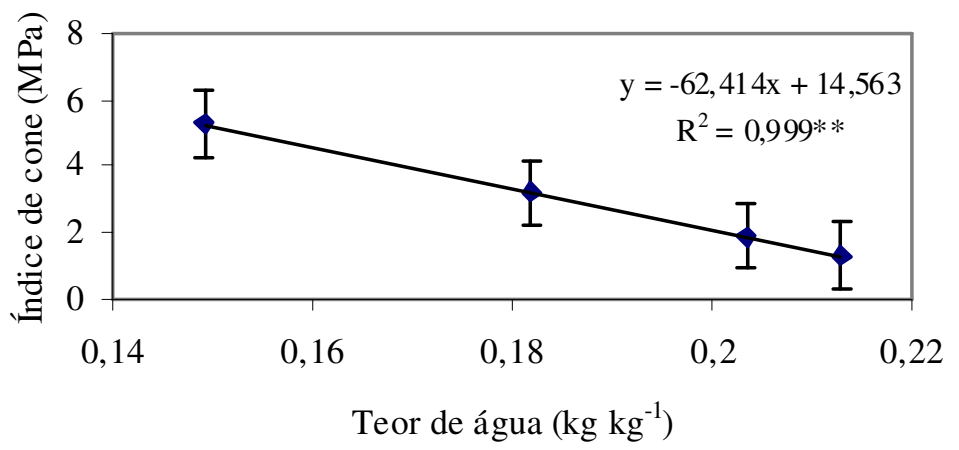

FIGURA 3. Equação entre índice de cone e teor de água - $\mathrm{IC}=f\left(\mathrm{H}_{2} \mathrm{O}\right)$. ** Significativo a $1 \%$. Equation between cone index and moisture - $\mathrm{CI}=f\left(\mathrm{H}_{2} \mathrm{O}\right)$. ** Significant at $1 \%$.

Verificou-se que, para os solos LVdf, NVdf e NVd, não houve diferenças significativas na determinação do índice de cone (Tabela 3), sendo o solo LVd diferente estatisticamente dos demais com menores valores. ROSOLEM et al. (1999), em estudo de RP em solo arenoso, observaram em menores proporções o aumento da RP do que em texturas mais argilosas.

O LVd apresentou maior diferença na sua textura (mais arenoso) (Tabela 1); assim, pode-se concluir que o índice de cone foi sensível a essa característica do solo. Segundo TORRES \& SARAIVA (1999), as diferenças entre a pressão das raízes e a resistência ao penetrômetro é menor nos solos arenosos e menos coesivos e maiores nos solos argilosos de alta coesão. SENE et al. (1985) consideram críticos os valores de RP que variam de 6,0 a 7,0 MPa, para solos arenosos, e em torno de 2,5 $\mathrm{MPa}$, para solos argilosos. 
TABELA 3. Análise estatística para os diferentes tipos de solos. Statistical analysis for the various soil types.

\begin{tabular}{ccc}
\hline Número de Determinações & Solos & Índice de Cone (MPa) \\
\hline 96 & LVdf & $3,20 \mathrm{~A}$ \\
96 & NVdf & $2,98 \mathrm{~A}$ \\
96 & NVd & $2,94 \mathrm{~A}$ \\
96 & LVd & $2,50 \mathrm{~B}$ \\
\hline
\end{tabular}

Médias seguidas da mesma letra não diferem, entre linhas, significativamente entre si, pelo teste de Tukey, a 5\% de probabilidade.

Observa-se que, no presente estudo, os valores de RP no solo arenoso (LVd) não atingiram o nível crítico.

Verificou-se que o teor de água foi um fator significativo na determinação do índice de cone, conforme mostrado na Tabela 4. Dados semelhantes foram encontrados por CUNHA et al. (2002) e SANTOS \& LANÇAS (1999).

TABELA 4. Análise estatística para o teor de água médio nos solos estudados. Statistical analysis for mean moisture in the soils studied.

\begin{tabular}{ccc}
\hline Número de Determinações & Toer de Água $\left(\mathrm{kg} \mathrm{kg}^{-1}\right)$ & Índice de Cone (MPa) \\
\hline 96 & 0,15 & $5,27 \mathrm{~A}$ \\
96 & 0,18 & $3,19 \mathrm{~B}$ \\
96 & 0,20 & $1,89 \mathrm{C}$ \\
96 & 0,21 & $1,28 \mathrm{D}$ \\
\hline
\end{tabular}

Médias seguidas da mesma letra não diferem, entre linhas, significativamente entre si, pelo teste de Tukey, a 5\% de probabilidade.

Analisando as Tabelas 2 e 4, observa-se que o teor de água do solo das avaliações situou-se dentro ou abaixo da faixa de friabilidade dos solos (LP - LC). Em razão dos resultados obtidos, a caracterização da faixa do teor de água na determinação da RP assume grande importância para a detecção das possíveis diferenças entre as áreas. Quando o teor de água aumenta, a RP diminui pela redução das forças de coesão que atuam entre as partículas de solo e aumento das forças de adesão, mudando a consistência de friável para plástica (HILLEL, 1998), atingindo valores limitantes ao crescimento de raízes em condições de baixo teor de água.

Para todos os solos estudados, houve influência significativa do teor de água nos resultados de índice de cone, com a dependência negativa entre os mesmos, conforme mostrado na Tabela 5.

Analisando a Tabela 5, observa-se que, à medida que diminui o teor de água, ocorre aumento significativo na RP. Os valores de resistência mais elevados foram registrados em todos os solos na condição de menor teor de água, ou seja, dentro ou abaixo da faixa de friabilidade do solo (mais próximo do limite de contração) (Tabela 2). Segundo TORRES \& SARAIVA (1999), é a faixa de friabilidade a indicada para detectar as possíveis diferenças na avaliação da RP.

Nas condições de solo mais úmido (próximo ao limite de plasticidade ou acima da faixa de friabilidade), os valores de RP podem ser considerados não impeditivos para os solos estudados. No entanto, com o secamento do solo, os valores de RP podem atingir níveis altamente impeditivos ao crescimento radicular (acima de 3,5 MPa), segundo TORRES \& SARAIVA (1999). 
TABELA 5. Interação solo x teor de água. Soil x moisture interaction.

\begin{tabular}{ccc}
\hline Solo & Teor de Água $\left(\mathrm{kg} \mathrm{kg}^{-1}\right)$ & Índice de Cone $(\mathrm{MPa})^{*}$ \\
\hline \multirow{2}{*}{ LVdf } & 0,1487 & $4,76 \mathrm{~A}$ \\
& 0,1818 & $2,37 \mathrm{~B}$ \\
& 0,2055 & $1,73 \mathrm{C}$ \\
\multirow{2}{*}{ NVdf } & 0,2142 & $1,15 \mathrm{D}$ \\
\hline & 0,1398 & $5,42 \mathrm{~A}$ \\
& 0,1756 & $3,39 \mathrm{~B}$ \\
\multirow{2}{*}{ NVd } & 0,1972 & $1,64 \mathrm{C}$ \\
& 0,2239 & $1,49 \mathrm{C}$ \\
\hline & 0,2219 & $5,83 \mathrm{~A}$ \\
& 0,2445 & $3,89 \mathrm{~B}$ \\
LVd & 0,2630 & $1,94 \mathrm{C}$ \\
& 0,2813 & $1,13 \mathrm{D}$ \\
\hline & 0,0859 & $5,07 \mathrm{~A}$ \\
& 0,1251 & $3,10 \mathrm{~B}$ \\
& 0,1387 & $2,25 \mathrm{C}$ \\
& 0,1525 & $1,33 \mathrm{D}$ \\
\hline
\end{tabular}

Médias seguidas da mesma letra não diferem, entre linhas, para cada solo, significativamente entre si, pelo teste de Tukey, a 5\% de probabilidade. * Média de 24 determinações.

Observa-se que, abaixo do teor de água de $0,18 \mathrm{~kg} \mathrm{~kg}^{-1}$ (Figura 3), os valores de RP abrangeram a faixa definida por TORRES \& SARAIVA (1999), em que ocorrem possíveis problemas de impedimento mecânico ao crescimento radicular, ou seja, valores de RP acima de 3,5 MPa. Dados corroboram DEXTER (1987), que observou, para uma mesma RP, quanto mais negativo for o potencial de água no solo (mais seco), menor será o crescimento radicular relativo.

O crescimento das raízes pode causar deformação do solo numa zona próxima à ponta das raízes, e a pressão exercida contra as partículas e/ou agregados deve ser suficiente para propiciar a penetração e o alongamento das raízes, sendo que valores excessivos de RP podem influenciar no crescimento das raízes em comprimento e em diâmetro (MEROTTO \& MUNDSTOCK, 1999). Dessa forma, o efeito da compactação tende a ser mais drástico ao crescimento radicular nas condições de solo seco.

Na prática, o conhecimento da relação entre a RP e o teor de água é de grande importância, pois permite prever as condições em que poderão ocorrer impedimento ou redução no crescimento radicular das plantas, permitindo, assim, manejo correto do solo (TORMENA et al., 2002).

\section{CONCLUSÕES}

Os maiores valores de resistência do solo à penetração foram detectados mais próximos do limite de contração do solo.

Os resultados mostraram correlação negativa entre o índice de cone e o teor de água, sendo a função de melhor ajuste a linear decrescente para todos os solos, com altos coeficientes de determinação.

Nas condições de solo mais úmido, os valores de resistência do solo à penetração podem ser considerados não impeditivos para o crescimento de raízes para os solos estudados.

O tipo de solo mostrou-se significativamente influente nos resultados de índice de cone, e os solos mais argilosos apresentaram valores mais elevados para esse índice do que o mais arenoso. 


\section{AGRADECIMENTOS}

À Fundação de Amparo à Pesquisa do Estado de São Paulo - FAPESP, pela concessão da bolsa ao aluno de graduação; aos Profs. Drs. Alberto K. Nagaoka e Pedro Castro Neto, pela gentil colaboração na realização deste trabalho.

\section{REFERÊNCIAS}

ARSHAD, M.A.; LOWERY, B.; GROSSMAN, B. Physical tests for monitoring soil quality. In: DORAN, J.W.; JONES, A.J. (Eds.). Methods for assessing soil quality. Madison: Soil Science of America, 1996. p.123-41 (SSSA Special Publication, 49).

ASAE. AMERICAN SOCIETY OF AGRICULTURAL ENGINEERS. Soil cone penetrometer. In: ASAE Standards 1999: standards engineering practices data. $46^{\text {th }}$ ed. St. Joseph, 1999. p.834-835 (ASAE S313.1).

ASHBURNER, J.E.; SIMS, B.G. Elementos de diseño del tractor y herramientas de labranza. San José: IICA, 1984. 474 p.

BENGOUGH, A.G.; MULLINS, C.E. Mechanical impedance to root growth: a review of experimental techniques and root growth responses. European Journal of Soil Science, Oxford, v.41, n.3, p.341-358, 1990.

BEUTLER, A.N.; CENTURION, J.F.; SILVA, A.P.; BARBOSA, J.C. Intervalo hídrico ótimo e produtividade de cultivares de soja. Revista Brasileira de Engenharia Agrícola e Ambiental, Campina Grande, v.10, n.3, p.639-645, 2006.

CAMARGO, O.A. de.; ALLEONI, L.R.F. Compactação do solo e o desenvolvimento das plantas. Piracicaba: Escola Superior de Agricultura “Luiz de Queiroz”, Universidade de São Paulo, 1997. $132 \mathrm{p}$.

CAMPBELL, D.J.; O'SULLIVAN, M.F. The cone penetrometer in relation to trafficability, compaction, and tillage. In: SMITH, K.A.; MULLINS, C.E. Soil analysis. New York: Marcell Dekker, 1991. p.399-423.

CANARACHE, A. PENETR - a generalized semi-empirical model estimating soil resistance to penetration. Soil Tillage Research, Amsterdam, v.16, n.1, p.51-70, 1990.

CASTRO NETO, P.; NAGAOKA, A.K.; LANÇAS, K.P. Agricultura de precisão: sistema de processamento de dados para elaboração de mapas de isocompactação. SIMPÓSIO EM ENERGIA NA AGRICULTURA, 1., 1999, Botucatu. Anais.... Botucatu: Universidade Estadual Paulista, 1999. p.449-453.

CHANCELLOR, W.J. Compaction of soil by agricultural equipment. Berkeley: University of California, Division of Agricultural Sciences, 1977. 53 p. (Bulletin, 1981)

CUNHA, A.R.; KLOSOWSKI, E.S.; GALVANI, E.; ESCOBEDO, J.F.; MARTINS, D. Classificação climática para o município de Botucatu - SP, segundo Köeppen. SIMPÓSIO EM ENERGIA NA AGRICULTURA, 1., 1999, Botucatu. Anais.... Botucatu: Universidade Estadual Paulista, 1999. p.487-491.

CUNHA, J.P.A.R. da; VIEIRA, L.B.; MAGALHÃES, A.C. Resistência mecânica do solo à penetração sob diferentes densidades e teores de água. Engenharia na Agricultura, Viçosa, v.10, n.1-4, p.1-7, 2002.

DEXTER, A.R. Mechanics of root growth. Plant and Soil, Dordrecht, v.98, n.3, p.303-12, 1987.

EMBRAPA. EMPRESA BRASILEIRA DE PESQUISA AGROPECUÁRIA. Centro Nacional de Pesquisa de Solos. Manual de métodos de análise de solo. 2. ed. Rio de Janeiro, 1997. 212 p. 
EMBRAPA. EMPRESA BRASILEIRA DE PESQUISA AGROPECUÁRIA. Centro Nacional de Pesquisa de Solos. Sistema brasileiro de classificação de solos. Rio de Janeiro, 1999. 412 p.

FORSYTHE, W. Física de suelos: manual de laboratório. San José: IICA, 1975. 212 p.

GOMES, A. de S.; PEÑA, Y.A. Caracterização da compactação através do uso do penetrômetro. Lavoura Arrozeira, Porto Alegre, v.49, n.1, p.18-20, 1996.

GUERRA, S.P.S.; LANÇAS, K.P.; MAZETTO, F.R. Utilização do GPS e do penetrômetro hidráulico-eletrônico para localização de pontos e avaliação da compactação do solo. REUNIÃO CIENTÍFICA EM CIÊNCIAS AGRÁRIAS DO LAGEADO, 7., 2000, Botucatu. Resumos... Botucatu: Universidade Estadual Paulista, 2000. p.85.

HENDERSON, C.W.L. Using a penetrometer to predict the effects of soil compaction on the growth and yield of wheat on uniform, sandy soils. Australian Journal of Agricultural Research, Melbourne, v.40, n.3, p.497-508, 1989.

HILLEL, D. Environmental soil physics. San Diego: Academic Press, 1998. 771 p.

KIEHL, E.J. Manual de edafologia: relações solo-planta. São Paulo: Editora Agronômica Ceres, 1979. $262 \mathrm{p}$.

KLEIN, V.A.; LIBARDI, P.L.; SILVA, A.P. Resistência mecânica do solo à penetração sob diferentes condições de densidade e teor de água. Engenharia Agrícola, Jaboticabal, v.18, n.2, p.45$54,1998$.

MEROTTO, A.; MUNDSTOCK, C.M. Wheat root growth as affected by soil strength. Revista Brasileira de Ciência do Solo, Viçosa - MG, v.23, p.197-202, 1999.

PEREIRA, J.O.; SIQUEIRA, J.A.C.; URIBE-OPAZO, M.A.; SILVA, S. de L. Resistência do solo à penetração em função do sistema de cultivo e teor de água do solo. Revista Brasileira de Engenharia Agrícola e Ambiental, Campina Grande, v.6, n.1, p.171-174, 2002.

REICHARDT, K. A água em sistemas agrícolas. São Paulo: Manole, 1990. 188 p.

ROSOLEM, C.A.; FERNANDEZ, E.M.; ANDREOTTI, M.; CRUSCIOL, C.A.C. Crescimento radicular de plântulas de milho afetado pela resistência do solo à penetração. Pesquisa Agropecuária Brasileira, Brasília, v.34, v.5, p.821-828, 1999.

SANTOS, C.A. dos; LANÇAS, K.P. Projeto e construção de um penetrômetro hidráulico-eletrônico. Energia na Agricultura, Botucatu, v.14, n.4, p.55-61, 1999.

SAS Institute. SAS language and prodecure: usage. Version 6. Cary, 1995. 373 p.

SENE, M.; VEPRAAKAS, M.J.; NADERMAN, G.C.; DENTON, H.P. Relationships of soil texture and structure to corn yield response to subsoiling. Soil Science Society of America Journal, Madison, v.49, n.2, p.422-427, 1985.

TORMENA, C.A.; BARBOSA, M.C.; COSTA, A.C.S. da; GONÇALVES, A.C.A. Densidade, porosidade e resistência à penetração em Latossolo cultivado sob diferentes sistemas de preparo do solo. Scientia Agrícola, Piracicaba, v.59, n.4, p.795-801, 2002.

TORRES, E.; SARAIVA, O.F. Camadas de impedimento do solo em sistemas agrícolas com a soja. Londrina: Embrapa Soja, 1999. 58 p. (Circular Técnica, 23). 